\title{
Correction to: "I just wish it becomes part of routine care": healthcare providers' knowledge, attitudes and perceptions of screening for maternal mental health during and after pregnancy: a qualitative study
}

Mary McCauley ${ }^{1 *}$, Abigail Brown ${ }^{1}$, Bernice Ofosu ${ }^{2}$ and Nynke van den Broek ${ }^{1}$

Correction to: BMC Psychiatry (2019) 19:279

https://doi.org/10.1186/s12888-019-2261-x

Following publication of the original article [1], we have been notified of a few mistakes in the display of the author names. The publisher apologizes for the inconvenience.

In this Correction the incorrect and correct author names are shown:

- Mary Mccauley should read Mary McCauley

- Brown Abigail should read Abigail Brown

- Ofosu Bernice should read Bernice Ofosu

- Nynke Van Den Broek should read Nynke van den Broek

The original article has been corrected.

\section{Author details}

${ }^{1}$ Centre for Maternal and Newborn Health, Liverpool School of Tropical Medicine, Pembroke Place, Liverpool L3 5QA, UK. ${ }^{2}$ Korle-Bu Teaching

Hospital, Accra, Ghana.

Published online: 18 October 2019

\section{Reference}

1. McCauley M, et al. "I just wish it becomes part of routine care": healthcare providers' knowledge, attitudes and perceptions of screening for maternal mental health during and after pregnancy: a qualitative study. BMC Psychiatry. 2019;19:279. https://doi.org/10.1186/s12888-019-2261-X.

\footnotetext{
* Correspondence: mary.mccauley@lstmed.ac.uk

${ }^{1}$ Centre for Maternal and Newborn Health, Liverpool School of Tropical

Medicine, Pembroke Place, Liverpool L3 5QA, UK

Full list of author information is available at the end of the article
}

(c) The Author(s). 2019 Open Access This article is distributed under the terms of the Creative Commons Attribution 4.0 International License (http://creativecommons.org/licenses/by/4.0/), which permits unrestricted use, distribution, and reproduction in any medium, provided you give appropriate credit to the original author(s) and the source, provide a link to the Creative Commons license, and indicate if changes were made. The Creative Commons Public Domain Dedication waiver (http://creativecommons.org/publicdomain/zero/1.0/) applies to the data made available in this article, unless otherwise stated. 